\title{
Diel diet shift of roach and its implications for the estimation of daily rations
}

\author{
S. S. HAERTEL ${ }^{*}+\$$ AND R. ECKMANN \\ *Institute of Freshwater Ecology and Inland Fisheries, Department Biology and Ecology \\ of Fishes, D-12587 Berlin, Germany; †University of Konstanz, Department of Biology, \\ Limnological Institute, D-78457 Konstanz, Germany
}

(Received 21 July 2001, Accepted 29 January 2002)

\begin{abstract}
In a small, 12 ha, mesotropic lake, roach Rutilus rutilus performed diel habitat shifts that clearly influenced the composition of their diet. During daytime, roach stayed in the littoral zone and concentrated on littoral prey. At night they were found in the pelagic zone, and pelagic prey items such as Daphnia spp. or Chaoborus flavicans dominated their food. On a seasonal scale, there were shifts in the importance of different food items and in the diel pattern of feeding intensity. Bioenergetics modelling in combination with an evacuation rate method for estimating daily rations allowed for changes in feeding modes to be taken into account, and so food item specific daily rations over the season could be determined. With the evacuation rate method applied on selected days, diel changes in diet compositions and feeding intensities could be quantitatively accounted for. When the $24 \mathrm{~h}$ integrated diet proportions were then used as an input parameter for bioenergetics modelling, food item specific consumption could be determined over the entire sampling season. The consideration of the diel diet shifts proved to be essential for the model output. If only the daytime or the night-time diet composition (derived from one single daily sampling) was taken into account for bioenergetics modelling, severe under- or overestimations of daily rations for specific food items resulted.

(C) 2002 The Fisheries Society of the British Isles
\end{abstract}

Key words: diel diet shift; daily ration; bioenergetics modelling; roach; Rutilus rutilus.

\section{INTRODUCTION}

Fishes can be considered as keystone species in lake ecosystems. They have the potential to directly or indirectly impact different trophic levels and thereby ecosystem structure and function (Northcote, 1988). Their behavioural flexibility, which means their ability to shift between prey types and habitats, might be one reason for this (Gliwicz \& Pijanowska, 1989). Omnivorous fishes, such as roach Rutilus rutilus L. (Winfield \& Nelson, 1991), that can use animal as well as plant diet, are the most pronounced examples of 'dietary' flexibility. Diet shifts are often closely linked to habitat shifts. Habitat shifts have been observed on different time and spatial scales. Diel inshore and offshore migrations are a well-documented example (Hall et al., 1979; Bohl, 1980; Wurtsbaugh \& Li, 1985; Naud \& Magnan, 1988; Gliwicz \& Jachner, 1992; Gauthier \& Boisclair, 1997). From the fishes' perspective, diel habitat shifts have often been interpreted as an optimal foraging behaviour with a behavioural trade-off between food resource utilization and predator avoidance (Gauthier \&

\$Author to whom correspondence should be addressed: Present address: Belle W. Baruch Institute for Marine Biology and Coastal Research, University of South Carolina, P.O. Box 1630, Georgetown, SC 29442, U.S.A. Tel.: +1 843 5463623; fax: +1 843 5461632; email: susanne@belle.baruch.sc.edu 
Boisclair, 1997). On a lake scale, habitat shifts can shape predation pressure patterns in space and time (Wurtsbaugh \& Li, 1985). For estimating food item specific daily rations of fishes, diel diet shifts are a methodological challenge. A certain item is often just consumed during a restricted time period, and feeding intensity varies in the course of a day. Two approaches are in common use for estimating (mean individual) daily rations, the evacuation rate methods (Eggers, 1977; Elliott \& Persson, 1978) and bioenergetics modelling (Hanson et al., 1997). The evacuation rate methods require extensive sampling effort over $24 \mathrm{~h}$ periods. The number of trials that can be conducted is therefore limited and only a number of 'point estimates' of daily ration will be available throughout a season. Bioenergetics models employ balanced energy equations to estimate daily ration by an individual as the sum of the physiological outputs in which it is manifested: growth, metabolism and waste products (Ney, 1990). As growth integrates feeding rate over time, effects of fluctuating environmental conditions are minimized, and the field data required can be obtained with moderate effort (Rice \& Cochran, 1984). The smallest time unit in bioenergetics modelling, however, is one day, and Horppila (1999) was able to show that food consumption estimates can be considerably biased when diel diet variation is not taken into account for the modelling process. For quantifying food consumption during time intervals shorter than 1 day and for identifying daily patterns of feeding intensity, the gut evacuation method of Elliot \& Persson (1978) is most appropriate, as it is based on sequential estimates of the amounts of food consumed between two consecutive samplings (Boisclair \& Leggett, 1988; Hölker \& Temming, 1996).

In Lake Grosser Vätersee, a small mesotrophic lake, diel habitat shifts were observed for roach, and found to be a main determinant of diet composition and therefore of predation on different food items. Roach preyed upon for example daphnids almost exclusively in the pelagic zone and only during a restricted time period of the day. This had to be taken into account, when zooplankton predation by roach had to be quantified as part of a comprehensive project on top-down control and cascading trophic interactions (Kasprzak et al., 2000). Bioenergetics modelling was combined with an evacuation rate method (Elliott \& Persson, 1978). With this combination, food item specific daily rations can be determined for fish that perform distinct diel diet and habitat shifts.

\section{MATERIALS AND METHODS}

\section{STUDY SITE}

Lake Grosser Vätersee (12 ha, maximum depth $11.5 \mathrm{~m}$, mean depth $5.2 \mathrm{~m}$, volume $633000 \mathrm{~m}^{3}$, linear lake basin form) is a mesotrophic to slightly eutrophic lake in the Baltic lake region of north-eastern Germany $\left(53^{\circ} 00^{\prime} \mathrm{N} ; 13^{\circ} 33^{\prime} \mathrm{E}, 60 \mathrm{~m}\right.$ a.s.1.). Details of its hydrography, trophic characteristics, submerged macrophytes and a preliminary characterization of the pelagic food web structure can be found in Kasprzak et al. (2000). In 1994, roach was the dominant fish species in terms of number as well as biomass (Radke, 1998; Kasprzak et al., 2000). Roach dominance was corroborated by gillnet catches in 1997 and 1998, and by an absolute population estimate using multiple mark-recapture experiments in 1998 (Haertel, 2001). Pike Esox lucius L., perch Perca fluviatilis L. $(\geq 150 \mathrm{~mm})$ and a small number of eel Anguilla anguilla L., which were stocked into the lake from 1993 to 1995, are the top predators (U. Baade \& K. Anwand, pers. comm.). 


\section{FISH DISTRIBUTION AND DIET}

Roach were sampled from two habitats, the littoral ( $\leq 3 \mathrm{~m}$ water depth) and the pelagic zone. Both habitats were sampled simultaneously during day and at night. Sampling took place monthly from May to September 1997 and from May to October 1998 with gillnets of $8-15 \mathrm{~mm}$ bar mesh size. In the littoral zone the nets were bottom set perpendicular to the shoreline. In the pelagic zone floating nets of $6 \mathrm{~m}$ depth were used. They fished almost the entire epilimnion, as the lake is thermally stratified from late April to late October, with an anoxic zone of up to $7 \mathrm{~m}$ water depth (Kasprzak et al., 2000). The nets were set for $2 \mathrm{~h}$ during the day (1000-1200 hours) and during the night. Night-time sampling started immediately after nightfall, and varied between 1930-2130 hours and 2245-0045 hours in 1997 and between 1900-2100 hours and 2300-0100 hours in 1998. The fish were stored on ice. Total length $\left(L_{\mathrm{T}}\right.$ to the nearest $\left.5 \mathrm{~mm}\right)$ and mass $(0 \cdot 1 \mathrm{~g})$ were recorded and scales taken for age determination. Catch per unit effort (CPUE) values were calculated per $100 \mathrm{~m}^{3}$ net panel and $2 \mathrm{~h}$ exposure time.

For diet analyses, roach $\geq 100 \mathrm{~mm} L_{\mathrm{T}}$ were stored whole in $5 \%$ formalin, while only the digestive tract was preserved from larger fish. Diet analyses were conducted for different length classes (1997: 65-84 mm, 85-104 mm, 105-154 mm; 1998: 65-84 mm, 85-104 mm, 105-124 mm, 125-144 mm). In the laboratory, fullness of the entire intestine was recorded on a 5 point scale $(0=$ completely empty to $4=$ wall very tense, content pressed; Bohl, 1980), while per cent composition of the diet by volume was assessed for the first third of the intestine.

For 1997 the share of daphnids in pelagic zooplankton was recorded on a 4 point scale (absent, $1-30 \%, 30-60 \%,>60 \%$ of the zooplankton diet). In 1998 three categories of pelagic zooplankton were distinguished: Daphnia spp., other pelagic cladocerans and Chaoborus flavicans larvae.

The roach length spectrum caught by gillnets of $8-15 \mathrm{~mm}$ bar mesh size was representative for the roach stock in Lake Grosser Vätersee. Larger length classes did not significantly contribute to the stock in 1997 and 1998, and age 0 year roach recruitment was negligible in both years (Haertel, 2001). Altogether, the 1995 year-class, which was age 3 years in 1998, dominated the stock throughout the investigation period (Haertel, 2001). Daily rations were estimated for this dominant age-class.

\section{DAILY RATION AND GUT EVACUATION METHOD}

Roach were sampled on 26-27 May, 21-22 July and 17-18 September 1998 at c. $2 \mathrm{~h}$ intervals over a period of $24 \mathrm{~h}$, starting at 0900 hours. They were sampled either by electrofishing (EFG/400: $4 \mathrm{~kW}, 200-610 \mathrm{~V}$, DC), with a beach seine ( $30 \mathrm{~m}$ long, $4 \mathrm{~mm}$ bar mesh) or with gillnets (10 and $12 \mathrm{~mm}$ bar mesh size; bottom set in the littoral zone, floating in the pelagic zone; maximum exposure time $20 \mathrm{~min}$ ). Based on observations of diel distribution in 1997 (Haertel, 2001), roach were sampled from the littoral zone during daytime and from the pelagic zone at night. They were killed with an overdose of MS 222 and preserved in 5\% formalin. From each sample, 10 fish (if available) were measured (to the nearest $\mathrm{mm}$ ) and their intestines were removed. The contents of the first third of the intestine as well as the fish together with its empty intestine were weighed (to the nearest 0.0001 and $0.01 \mathrm{~g}$, respectively), dried to constant mass $\left(80^{\circ} \mathrm{C}\right)$ and weighed again. Intestine fullness $\mathrm{F}$ was expressed as $\mathrm{mg} \mathrm{g}^{-1}$ on both wet and dry mass basis. Additionally, per cent composition of the diet by volume was assessed four to seven times during each $24 \mathrm{~h}$ period, depending on sample availability.

Evacuation rates were determined separately for day and night, since they were expected to differ between animal and plant diets (Persson, 1982). For daytime evacuation experiments, the serial slaughter approach (Heroux \& Magnan, 1996) was followed. Roach were caught by electrofishing or with a beach seine, and 15-20 fish were killed and preserved immediately. The remaining fish were divided into groups of 15-20 fish. Each group was kept in a plastic bag $(0.6 \times 1.2 \mathrm{~m})$ filled with filtered $(50 \mu \mathrm{m})$ and aerated lake water to $0.8 \mathrm{~m}$ depth. The bags were placed in the littoral zone at $0.8 \mathrm{~m}$ depth so that the experimental fish would be at the same temperature experienced by wild fish. Every $1 \mathrm{~h}$ (July experiment) or every $2 \mathrm{~h}$ (May and September experiments), the fish in one bag were killed and preserved. Samples were processed as described above. At 
night when roach stayed in the pelagic zone, they could not be caught alive but with gillnets only. Therefore, fish from the regular night-time samples were taken and processed as described above. Night-time evacuation rate was then calculated from the decrease in intestine fullness after the onset of darkness (Ney, 1990). All three $24 \mathrm{~h}$ fisheries were conducted during a new moon, and no recently ingested food was found in the intestines at night. Food evacuation rates and daily rations were calculated from the data on intestine fullness according to Elliott \& Persson (1978). Evacuation rate was assumed to be exponential (Persson, 1982). By integrating the information on changing diet composition over the $24 \mathrm{~h}$ period into the calculation process, daily rations were obtained separately for the different food categories. The resulting per cent composition of the entire daily ration integrated the roach's diel diet shifts and changes in feeding intensity quantitatively, and was used as an input parameter for bioenergetics modelling.

\section{DAILY RATION AND BIOENERGETICS MODELLING}

For bioenergetics modelling, the energy balance model of (Kitchell et al., 1977) in the computerized version of Hanson et al. (1997) was used. According to this model, the energy consumed is balanced with the energy expended and gained (Kitchell et al., 1977). The basic equation is: $C=(R+A+S)+(F+U)+G$ where $C=$ consumption, $R=$ standard respiration, $A=$ active metabolism, $S=$ specific dynamic action (costs) of digestion, $F=$ egestion, $U=$ excretion, $G=$ somatic growth .

Consumption rate is modelled as a function of body mass and temperature. The model initially determines the proportion of the maximum feeding rate at the respective temperture, that had to be consumed by the fish ( $P$-value) to fit observed growth. This $P$-value is then used to estimate prey-specific consumption for the growth interval between the observed start and end masses. To account for interseasonal variation in growth, $P$-values were individually determined for each of the intervals between fish sampling dates instead of for the whole season interval. Species-specific physiological parameters for roach were taken from Horppila \& Peltonen (1997). Consumption and respiration were assumed to follow the temperature and size dependent TDEP-Model (Kitchell et al., 1977), which is recommended for warm-water species. Egestion rate was estimated as a constant proportion of consumption, depending on the digestibility of the different food categories, and excretion was estimated as a constant proportion of assimilated energy (Horppila \& Peltonen, 1997). The composition of absolute daily rations of roach determined by the evacuation rate model was taken as diet input data for the model. It quantitatively integrates the diel diet shifts observed for roach, as both changing diet composition and changing feeding intensities are taken into account. Calorie densities were assumed to be $2512 \mathrm{~J} \mathrm{~g} \mathrm{wm}^{-1}$ for zooplankton (Hewett \& Johnson, 1992), $1838 \mathrm{~J} \mathrm{~g} \mathrm{wm}^{-1}$ for C. Alavicans and $3944 \mathrm{~J} \mathrm{~g} \mathrm{wm}^{-1}$ for benthos (Cummins \& Wuycheck, 1971). Caloric densities of roach, sediment, macrophytes (Chara sp., Myriophyllum sp., Ceratophyllum demersum) and the filamentous alga Vaucheria dichotoma were determined by bomb calorimetry in duplicate samples (Automatic MK 200, MORAT, calibrated with benzoic acid) from Lake Grosser Vätersee samples taken on 27 May, 22 July and 18 September 1998 (Table I). For plant diet, the mean of the different macrophyte species plus $V$. dichotoma for the respective date was used as model input. Assimilation efficiencies of macrophytes, filamentous algae and detritus were assumed to be $0 \cdot 5$ (Persson, 1983).

For determining somatic growth, roach were caught by electrofishing or with a beach seine in May $(n=196)$, June $(n=142)$, July $(n=307)$ and September $(n=168) 1998$. They were measured to the nearest $1 \mathrm{~mm}$ and weighed to the nearest $0 \cdot 1 \mathrm{~g}$. Scales were taken for age determination. Since length distributions of different age classes overlapped considerably, an algorithm (Hasselblad, 1966; in the computerized version of Gayanilo et al., 1996) was used to separate age classes. This method applies the maximumlikelihood concept to separate a polymodal distribution into unimodal components where the user defines the number of unimodal distributions in advance. Finally, from the estimated mean $L_{\mathrm{T}}$ of age 3 year roach, their growth during the summer of 1998 was calculated. 
TABLE I. Caloric densities of roach, sediment and different plant species from Lake Grosser Vätersee in 1998. Values were determined by bomb calorimetry in duplicate samples

\begin{tabular}{lccc}
\hline & \multicolumn{3}{c}{ Caloric density $\left(\mathrm{J}^{\mathrm{g} \text { wet mass }}{ }^{-1}\right)$} \\
& 27 May & 22 July & 18 September \\
\hline Roach & 4258 & 5238 & 5179 \\
Sediment & 2189 & 1240 & 1824 \\
Vaucheria dichotoma & 893 & 1757 & - \\
Myriophyllum sp. & 1022 & 1560 & 1581 \\
Chara sp. & 1199 & 1399 & 1233 \\
Ceratophyllum demersum & - & 1277 & 1405 \\
& & & \\
\hline
\end{tabular}

Water temperature was recorded at $1 \mathrm{~h}$ intervals throughout the sampling season at 0 , 1 and $3 \mathrm{~m}$ water depth in the pelagic zone and at one shallow littoral site. As a model input, a volume-weighted mean temperature from the pelagic recordings was calculated for each day and smoothed by 5 day running averages. Temperature at the littoral location was on average $0.5^{\circ} \mathrm{C}( \pm 1.9$ S.D. $)$ below those at $0 \mathrm{~m}$ in the pelagic zone. These data were excluded from further analysis because they were registered in the very shallow surf zone where roach did not stay.

\section{RESULTS}

\section{DISTRIBUTION}

Catches of roach in the littoral and pelagic zones differed significantly between day and night on all sampling dates $(P<0 \cdot 01,2 \times 2$ contingency table $)$. During daytime roach were exclusively caught in the littoral zone while at night $>90 \%$ of the roach were obtained from the pelagic zone in both study years (Haertel, 2001).

\section{DIET}

The diet of roach obtained from monthly gillnet sampling differed markedly between day and night in both study years. During the day, when roach were found inshore, they consumed littoral food items almost exclusively in both years (Fig. 1). At night, when roach stayed in the pelagic zone, their food was dominated by pelagic zooplankton in May, June, July and late September 1997 as well as throughout May to October 1998 (Fig. 1). Daphnids were the most important planktonic prey from spring to early summer and in autumn of both years. Although Fig. 1 shows the diet composition of roach $85-104 \mathrm{~mm} L_{\mathrm{T}}$, the diet pattern observed was consistent throughout all length classes studied (65-154 mm; Haertel, 2001).

These diel diet shifts were more comprehensively studied over $24 \mathrm{~h}$ periods for three dates in 1998 (26-27 May, 21-22 July, 17-18 September) as part of the $24 \mathrm{~h}$ sampling schedule for the estimation of daily rations. Again, clear differences in diet composition of roach between day and night samples were found in May and July 1998 (Fig. 2). In May, during the daytime, littoral food components and cladocerans other than Daphnia sp. were taken, whereas at night daphnids constituted up to $91 \%$ of the diet. In July, benthos and plant material were eaten 

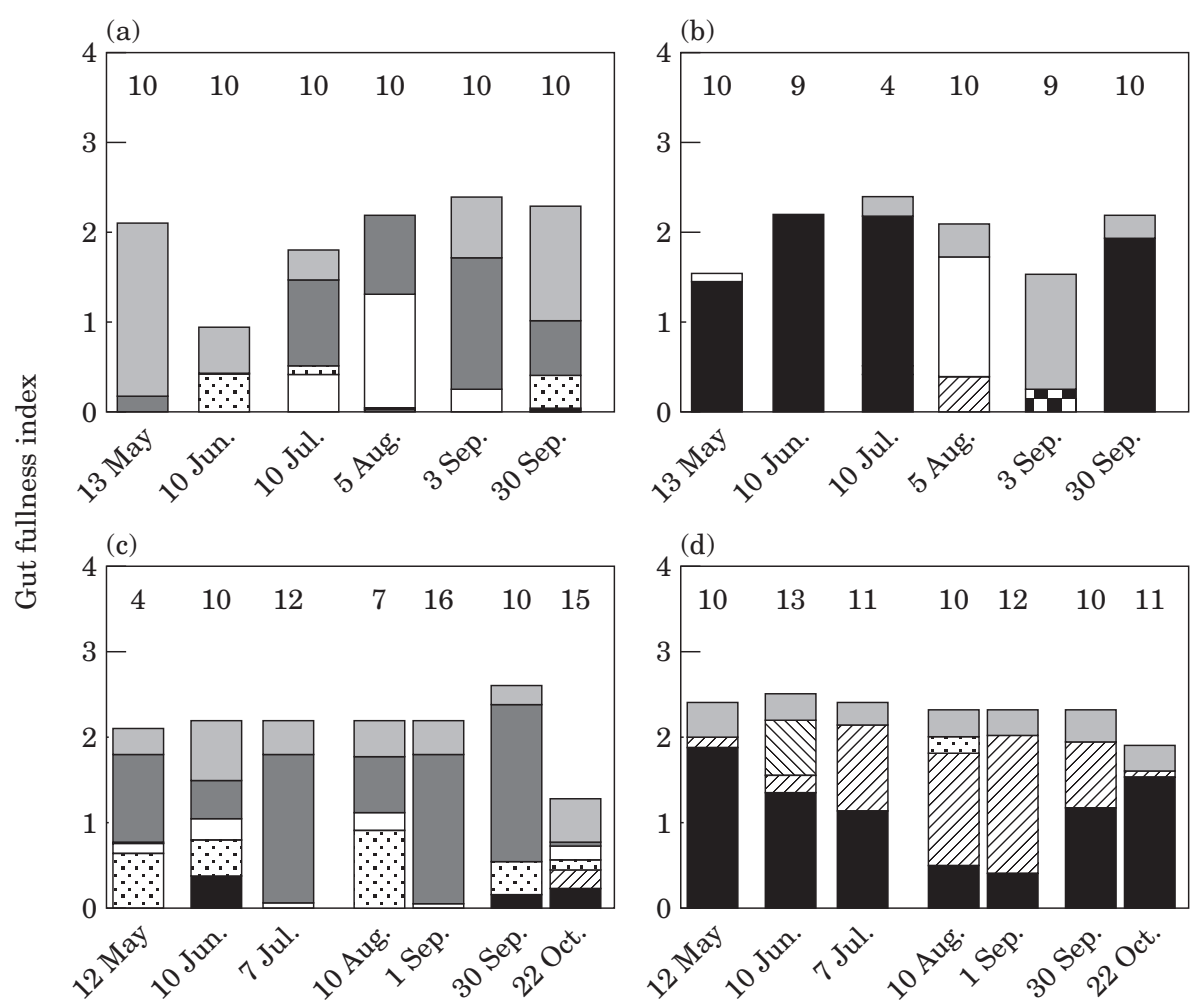

FIG. 1. Mean gut fullness of the $85-104 \mathrm{~mm}$ length class of roach sampled in the littoral zone during the day in 1997 (a) and 1998 (c) and in the pelagic zone during the night in 1997 (b) and 1998 (d). For 1997, the share of daphnids in the roach's pelagic zooplankton diet is given on a four level scale (absent, $1-30 \%, 30-60 \%, \geq 60 \%$ ). Numbers above columns are sample sizes. 1997 . pelagic zooplankton with increasing share of daphnids $(\mathbb{Z})$; 1998: Daphnids $(\mathbf{\square})$, other pelagic zooplankton $(\varangle)$, C. flavicans $(\mathbb{\nabla}) ; 1997$ and 1998: macrozoobenthos, other insects ( $\square$ ), littoral zooplankton ( $\square$ ), filamentous algae, macrophytes $(\square)$ and detritus ( $\square$ ).

throughout the day, while $C$. flavicans contributed up to $73 \%$ to the night diet. In September throughout the whole day, $34-79 \%$ of the diet were cladocerans (other than Daphnia sp.). Bosmina sp. was eaten during the day, whereas at night, Leptodora kindtii was taken. As both these items were recorded within the same food category, no separate quantitative percentages can be given.

\section{DAILY RATION AND DIRECT METHOD}

Evacuation rates could be determined experimentally and from field sampling only in May (Table II). The rate was higher in the daytime, when the diet was mainly composed of plant material, and it was lower during the night, when the diet was mainly of animal origin. In July and September, daytime evacuation experiments were started at $c .1100$ hours. In both cases, gut fullness was too low to permit reliable evacuation measurements. Additionally, night-time evacuation rates could not be determined, since periods with no food intake were too short. For July and September therefore, May evacuation rates were temperature adjusted according to Persson (1982) (Table II) and then used for 

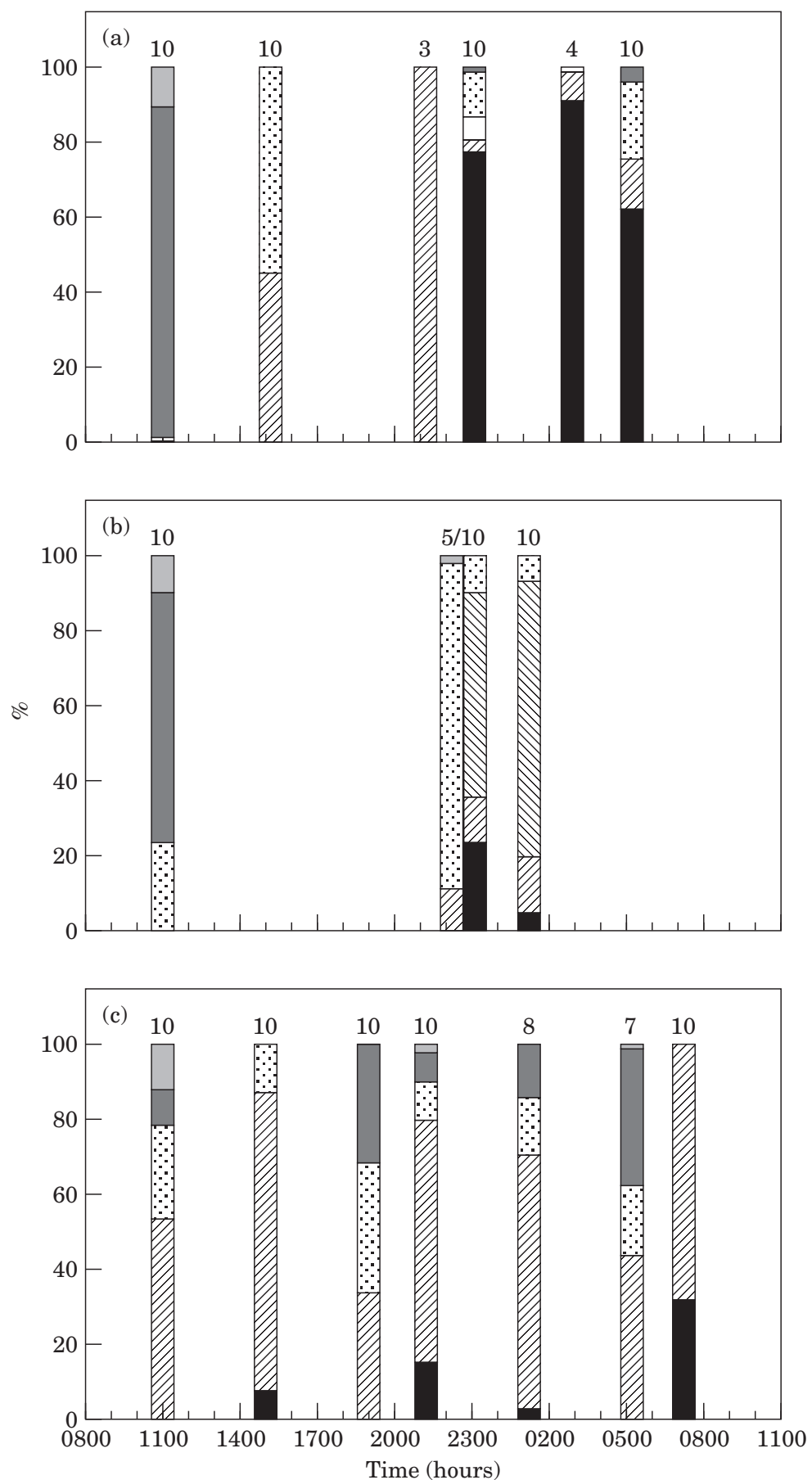

FIG. 2. Per cent diet composition by volume of age 3 year roach during three $24 \mathrm{~h}$ periods (a) 26-27 May, (b) 21-22 July and (c) 17-18 September in 1998. Fish were sampled in the littoral zone during the day and in the pelagic zone during the night. Numbers above columns are sample sizes. Daphnids $(\square)$, other zooplankton $(\mathbb{Z})$, C. flavicans $(\mathbb{Q})$; macrozoobenthos $(\square)$, filamentous algae and macrophytes $(\square)$ and detritus $(\square)$. 
TABLE II. Evacuation rates $R\left(\mathrm{~h}^{-1}\right)$ of age 3 year roach in Lake Grosser Vätersee in 1998 determined separately for day and night

\begin{tabular}{|c|c|c|c|c|c|}
\hline \multirow[t]{2}{*}{ Date } & \multirow{2}{*}{$\begin{array}{c}\text { Water } \\
\text { temperature } \\
\left({ }^{\circ} \mathrm{C}\right)\end{array}$} & \multicolumn{2}{|c|}{$\begin{array}{c}R \text { based on } \\
\text { dry mass }\end{array}$} & \multicolumn{2}{|c|}{$\begin{array}{l}R \text { based on } \\
\text { wet mass }\end{array}$} \\
\hline & & Day & Night & Day & Night \\
\hline 26-27 May & $16 \cdot 1$ & $0 \cdot 2825$ & $0 \cdot 1296$ & $0 \cdot 2047$ & $0 \cdot 0915$ \\
\hline 21-22 July* & $21 \cdot 4$ & $0 \cdot 5149$ & $0 \cdot 2362$ & $0 \cdot 3731$ & $0 \cdot 1668$ \\
\hline 17-18 September* & $15 \cdot 9$ & $0 \cdot 2742$ & $0 \cdot 1258$ & $0 \cdot 1987$ & $0 \cdot 0888$ \\
\hline
\end{tabular}

*Data calculated from May evacuation rates by temperature adjustment according to Persson (1982).

calculating daily rations. According to Persson (1982), for roach the relation between the evacuation rate $R$ and the temperature can be described by the exponential function $R=a e^{\mathrm{bT}}$, with $a=0.0032$ and $b=0 \cdot 115$. From this function, ' theoretical ' evacuation rates were calculated for the respective temperatures at the three sampling dates in Lake Grosser Vätersee. Then a factor was established that described the relationship between the 'theoretical' evacuation rate in May to the 'theoretical' rates in July and September, respectively. These factors were then used to adjust the measured evacuation rate in May in Lake Grosser Vätersee for the temperatures in July and September 1998.

In May, median gut fullness was highest at $c .1200$ hours $\left(2 \cdot 1 \mathrm{mg} \mathrm{dm} \mathrm{g} \mathrm{dm}^{-1}\right)$

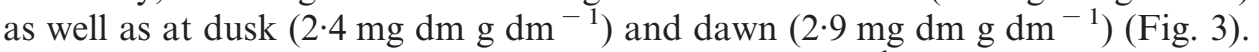
In July, gut fullness increased up to $4.2 \mathrm{mg} \mathrm{dm} \mathrm{g} \mathrm{dm}^{-1}$ at 1330 hours, but no crepuscular peaks were recorded. In September, gut fullness always remained $<1.4 \mathrm{mg} \mathrm{dm} \mathrm{g} \mathrm{dm}{ }^{-1}$ and no distinct fluctuations could be observed in the course of the day.

From gut fullness, food intake was calculated for the time periods between sampling events. In May, the rate of food consumption per hour peaked at 1200 hours $\left(0.8 \mathrm{mg} \mathrm{dm} \mathrm{g} \mathrm{dm}{ }^{-1} \mathrm{~h}^{-1}\right)$, dusk $\left(1.6 \mathrm{mg} \mathrm{dm} \mathrm{g} \mathrm{dm}{ }^{-1} \mathrm{~h}^{-1}\right)$ and dawn $\left(1.3 \mathrm{mg} \mathrm{dm} \mathrm{g} \mathrm{dm}^{-1} \mathrm{~h}^{-1}\right)$. In July, the highest consumption rate of all sampling periods $\left(2.9 \mathrm{mg} \mathrm{dm} \mathrm{g} \mathrm{dm}{ }^{-1} \mathrm{~h}^{-1}\right)$ was recorded at $c .1200$ hours. In September, the rate of food consumption never exceeded $0.5 \mathrm{mg} \mathrm{dm} \mathrm{g} \mathrm{dm}{ }^{-1} \mathrm{~h}^{-1}$ throughout the day. Relative and absolute daily rations for all food items combined were highest in July, as was water temperature (Table III). The proportion of daphnids in the daily ration was highest in May (Fig. 4). In July, when the overall daily ration was highest, littoral food components (mainly filamentous algae, macrophytes, detritus and insects) formed $85 \%$ of the diet (Fig. 4), and were also the major energy source (Fig. 5). Seventy-one per cent of the littoral food eaten were filamentous algae and macrophytes (Fig. 4). In September, when zooplankton (other than Daphnia spp.) was eaten throughout the day (Fig. 2), this category accounted for $63 \%$ of the daily ration (Fig. 4).

Roach occurred in the pelagic zone from dusk to dawn, i.e. they spent $c .7 \mathrm{~h} \mathrm{in}$ this habitat in May, $6 \mathrm{~h}$ in July and $10 \mathrm{~h}$ in September (Fig. 3). During this time, they consumed between 21 and $55 \%$ of their daily ration in terms of dry mass and between 30 and $62 \%$ in terms of energy (Fig. 5). 


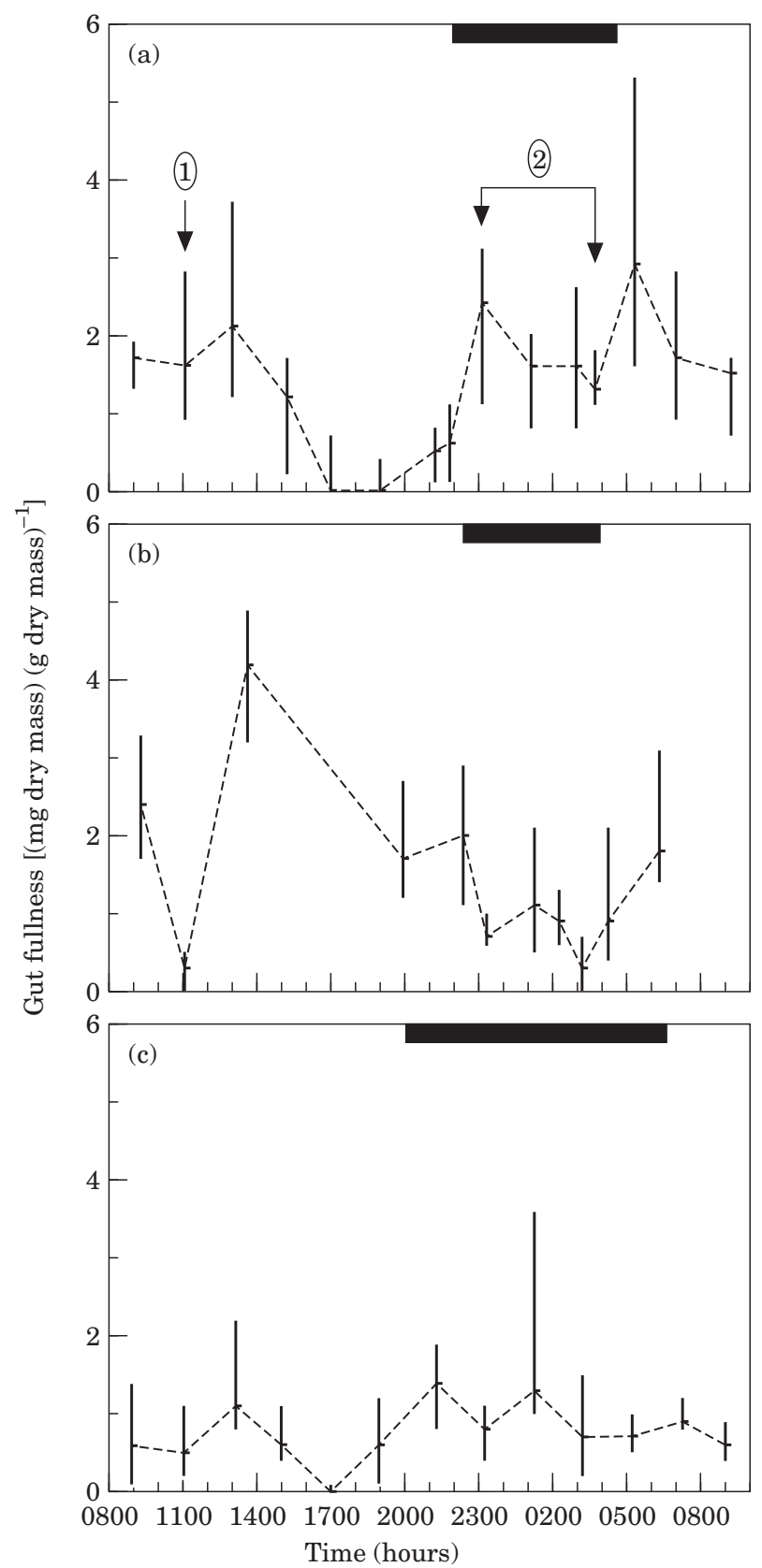

FIG. 3. Median gut fullness of roach with corresponding upper and lower quartiles during three $24 \mathrm{~h}$ periods (a) 26-27 May, (b) 21-22 July and (c) 17-18 September in 1998. The black bars at the top of each graph represent the time periods, when roach were caught in the pelagic zone. 1, starting point of the daytime evacuation experiment; 2 , time period used for the calculation of the night-time evacuation rate. 
TABLE III. Absolute $\left(D R_{\text {total }}\right)$ and relative $\left(D R_{\text {relative }}\right)$ daily rations for all food items combined, of age 3 year roach in 1998 derived from the evacuation rate mdel

\begin{tabular}{lccccc}
\hline Date & $\begin{array}{c}\text { Temperature } \\
\left({ }^{\circ} \mathrm{C}\right)\end{array}$ & $\begin{array}{c}D R_{\text {total }} \\
(\mathrm{mg} \mathrm{dm})\end{array}$ & $\begin{array}{c}D R_{\text {total }} \\
(\mathrm{mg} \mathrm{wm})\end{array}$ & $\begin{array}{c}D R_{\text {relative }} \\
(\% \mathrm{dm})\end{array}$ & $\begin{array}{c}D R_{\text {relative }} \\
(\% \mathrm{wm})\end{array}$ \\
\hline 26-27 May & $16 \cdot 1$ & $10 \cdot 2$ & 124 & $0 \cdot 9$ & $2 \cdot 0$ \\
21-22 July & $21 \cdot 4$ & $35 \cdot 6$ & 332 & $2 \cdot 1$ & $4 \cdot 1$ \\
17-18 September & $15 \cdot 9$ & $13 \cdot 0$ & 204 & $0 \cdot 5$ & $1 \cdot 7$ \\
\hline
\end{tabular}

dm, Dry mass; wm, wet mass.

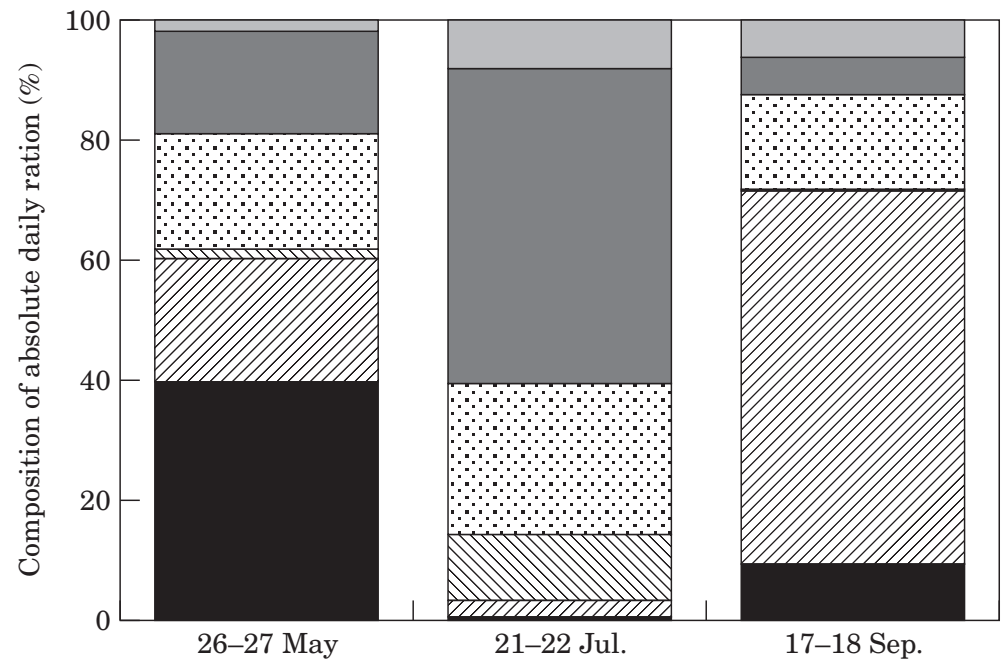

FIG. 4. Per cent composition of the daily ration of age 3 year roach for three $24 \mathrm{~h}$ periods in 1998 . Values are based on an evacuation rate model with evacuation rates determined separately for day and

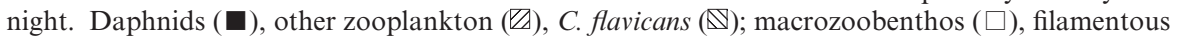
algae and macrophytes $(\square)$ and detritus $(\square)$.

\section{DAILY RATION AND BIOENERGETICS MODELLING}

Age 3 year roach grew from $87 \mathrm{~mm}\left( \pm 5 \mathrm{~mm}\right.$ S.D.) mean $L_{\mathrm{T}}$ at the beginning of the sampling season to $107 \mathrm{~mm}( \pm 8 \mathrm{~mm})$ mean $L_{\mathrm{T}}$ in September [10 June: $89 \mathrm{~mm}( \pm 7 \mathrm{~mm}) ; 22$ July: $96 \mathrm{~mm}( \pm 7 \mathrm{~mm})$ ]. This low length-at-age and slow growth is characteristic for mesotrophic lakes in this region (Radke, 1998).

The diet composition over $24 \mathrm{~h}$ derived from the evacuation rate model (Fig. 4) was used as an input for the bioenergetics model. The proportion of physiological maximum consumption realized ( $P$-value) by roach in Lake Grosser Vätersee never exceeded 0.5 (26 May-9 June, 0.395; 10 June-20 July, 0.487; 21 July-17 September, 0.475). Absolute daily ration for all food categories combined by one age 3 year roach specimen ranged from 261 to $660 \mathrm{mg}$ wet mass for the period from May to September 1998 (Fig. 6). The absolute daily ration of daphnids by roach was highest in May and June (up to $149 \mathrm{mg}$ wet mass) (Fig. 6), while macrophytes and detritus dominated during the 

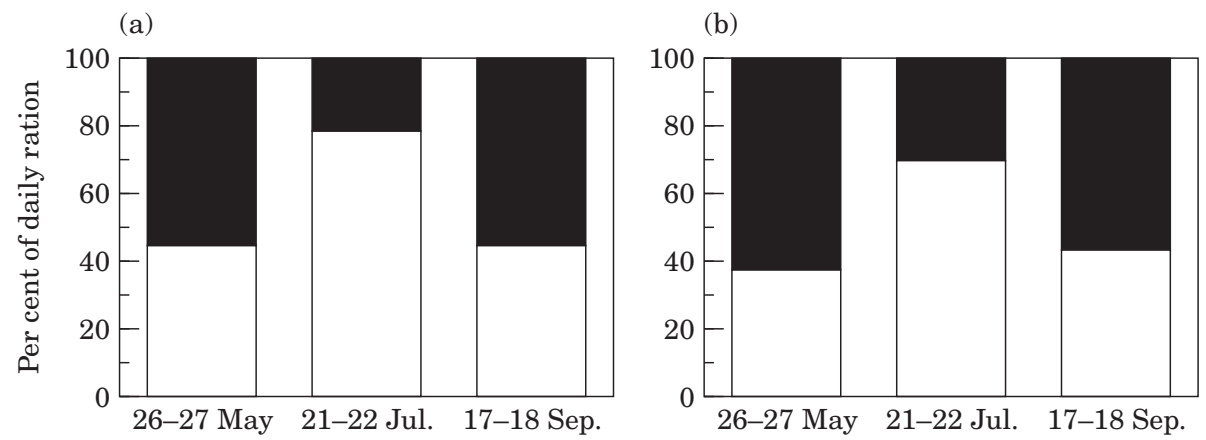

FIG. 5. Per cent of daily ration consumed by age 3 year roach in the daytime ( $\square$, littoral zone) and night-time ( $\boldsymbol{\square}$, pelagic zone) habitat, calculated in terms of dry mass (a) and energy (b).

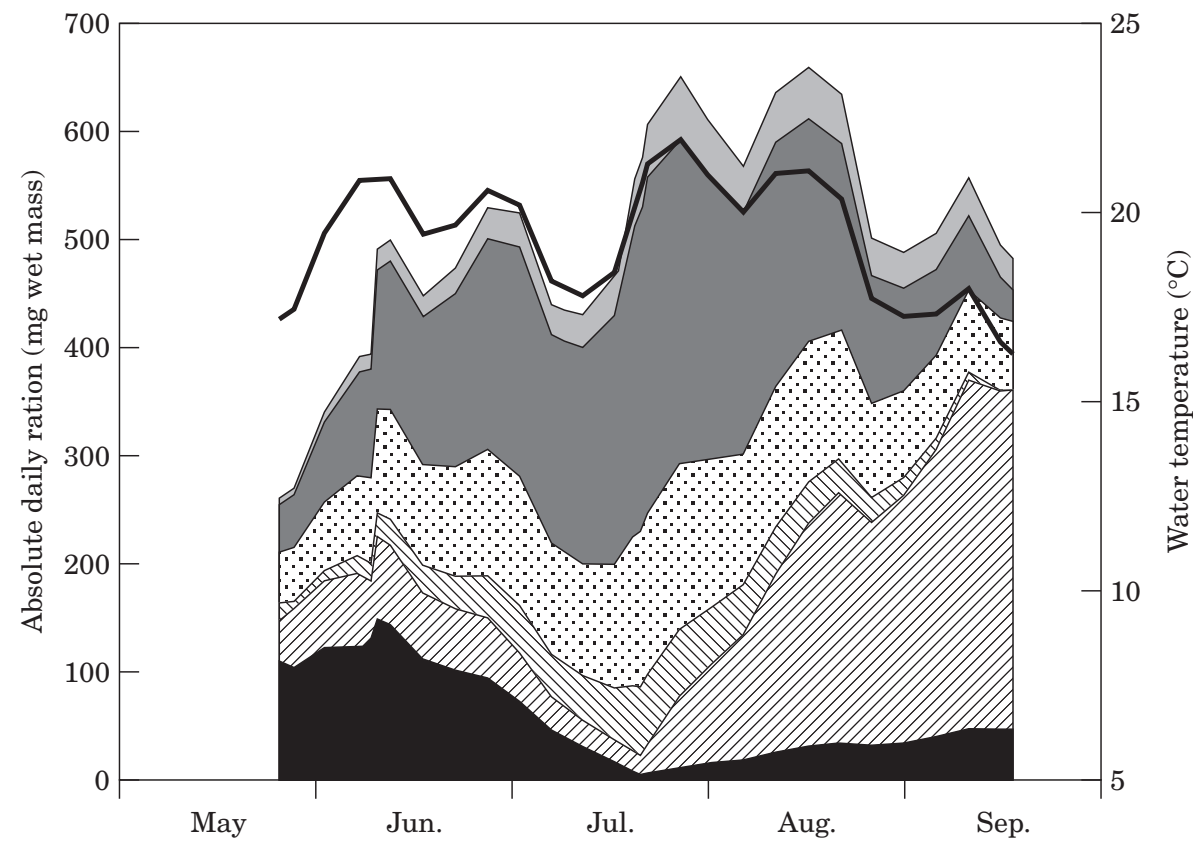

FIG. 6. Absolute daily rations of different food items of an age 3 year roach individual during summer 1998 in Lake Grosser Vätersee, and epilimnetic water temperature (-). Daily rations were estimated by bioenergetics modelling. Daphnids $(\boldsymbol{\square})$, other zooplankton $(\mathbb{Z})$, C. flavicans $(\mathbb{\nabla})$; macrozoobenthos $(\square)$, filamentous algae and macrophytes $(\square)$ and detritus $(\square)$.

summer (up to 310 and $51 \mathrm{mg}$ wet mass, respectively) and other zooplankton became more important in the autumn (up to $322 \mathrm{mg}$ wet mass).

Most studies use diet composition derived from a single sampling at a certain time of the day as a model input parameter. In the next step therefore the relevance of diurnal variations in diet composition and feeding intensity for the model output was assessed. Daphnia spp. was chosen as an example of a food category. Roach predation on Daphnia spp. in Lake Grosser Vätersee was 


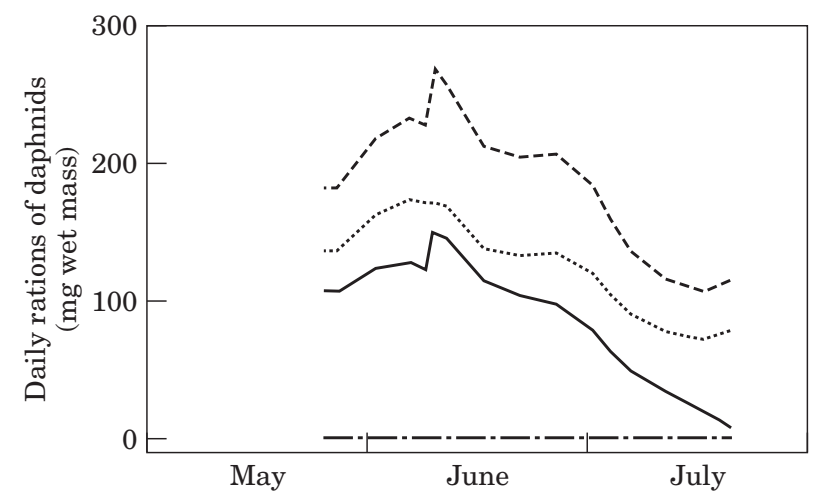

FIG. 7. Absolute daily ration of daphnids for an age 3 year roach individual derived from bioenergetics modelling. Four different situations are compared based upon different diet compositions as model input: (1) — - - daytime diet composition (determined from samples taken at 1100 hours); (2) _ - - , night-time diet composition (determined from samples taken at 2315 hours); (3) - . - - , the mean of these two diet compositions, and (4) _ calculated with an evacuation rate model (cf. Fig. 4).

strongly daytime dependent, and many food-web studies have examined the consumption of Daphnia spp. by fishes.

For the time period from May to July, when the consumption of daphnids was most intense, additional bioenergetics modelling was performed under three different situations and compared with the results of the baseline model. In the first and second situations, the daytime (1100 hours) or night-time (2315 hours) diet composition, respectively, was used as a model input (Fig. 2), while in the third situation the mean diet composition of these two sampling times was used. Under the first situation, no consumption of daphnids was found at all (Fig. 7). Under the second situation, the consumption of daphnids was 2-20 times higher as compared with the baseline model (=diet composition over $24 \mathrm{~h}$ as model input). Under the third situation, the estimates for May and June were 1.1-1.5 times higher than those derived from the baseline model. In July, the differences between the baseline model and situation 3 were more pronounced, as on 21-22 July daphnids accounted for only $0.6 \%$ of the absolute daily ration (cf. Fig. 5), but were present in the diet (23\%) at 2315 hours (cf. Fig. 2).

\section{DISCUSSION}

Regular diel horizontal migrations of roach ( $\geq 1$ year) strongly influenced their diet composition, and were therefore key factors in understanding roach predation on different food items in the small mesotrophic Lake Grosser Vätersee. Feeding of roach on Daphnia spp., C. flavicans or other pelagic food items was mainly restricted to the period from dusk to dawn, when roach migrated to, or stayed in the pelagic zone. Macrophytes, deritus and macrozoobenthos were consumed during this daytime, littoral residence.

Diel habitat shifts, like those observed in Lake Grosser Vätersee for roach of age $\geq 1$ year, are widespread among planktivorous fishes (Hall et al., 1979; Bohl, 1980; Wurtsbaugh \& Lie, 1985; Gliwicz \& Jachner, 1992). They have often been 
regarded as an optimal foraging behaviour with a trade-off between food resource utilization and predator avoidance (Gauthier \& Boisclair, 1997). In Lake Grosser Vätersee, the littoral was not a profitable foraging habitat for roach, since macrozoobenthos and zooplankton generally reached only low biomass values (Radke, 1998; F. Hölker \& S. Haertel, unpubl. data). Indeed, roach fed on filamentous algae, macrophytes and deritus during their daytime residence in the littoral zone. The pelagic zone was probably much more profitable because of the presence of zooplankton and the high foraging efficiency of roach on zooplankton in open waters (Persson, 1987), but during the daytime the predation risk was high in this habitat. Schools of large piscivorous perch were observed in the pelagic zone during the daytime, while at night these predators rested in shallow littoral areas (U. Baade, pers. comm.). Moreover, great crested grebes Podiceps cristatus were present throughout the summer. Through diel horizontal migrations, roach gained access to pelagic zooplankton in addition to littoral food resources, and they kept predation risk as low as possible.

Roach spent $7-10 \mathrm{~h}$ in the pelagic zone, where they consumed up to $55 \%$ of their daily ration in terms of dry mass and up to $60 \%$ in terms of energy. Horizontally migrating dace Phoxinus eos $\times P$. neogaeus Cope in a small Canadian lake obtained on average $70 \%$ of their daily ration from offshore. Despite significantly higher activity costs, they still had a net benefit compared to dace experimentally restricted to the littoral zone (Gauthier \& Boisclair, 1997). In Lake Grosser Vätersee, growth and activity costs of roach have been simulated with an individual-based model (IBM) that is based on food utilization, bioenergetics, spatial distribution and seasonal influences (Hölker, 2000), and that was parameterized for the lake (Hölker et al., in press). A significantly lower seasonal length increment resulted for a model situation, in which roach were restricted to the littoral zone compared to a situation that allowed for the observed diel horizontal migrations, despite activity costs that were c. $60 \%$ (over the season) higher in the latter situation (Hölker et al., in press).

Seasonal diet shifts of roach in Lake Grosser Vätersee can be interpreted as a reaction to changing absolute and relative food availability. Daphnids dominated the crepuscular and nocturnal diet of roach in spring, when they were most abundant (20.5 $\mathrm{g} \mathrm{wm} \mathrm{m}^{-2}$ on 28 May, S. Steiner, pers. comm.). Roach's feeding activity then peaked during dusk and dawn. In July daphnid biomass was distinctly lower $\left(0.8 \mathrm{~g} \mathrm{wm} \mathrm{m}^{-2}\right.$ on $23 \mathrm{July}$, S. Steiner, pers. comm.) and roach in the pelagic zone switched to $C$. flavicans larvae. Vertically migrating $C$. flavicans larvae are available in the epilimnion of the lake during the night only (I. Jäger, pers. comm.), and no increased crepuscular feeding activity was observed. In September, C. flavicans larvae abundance had decreased (3rd and 4th instars: $0.3 \mathrm{~g} \mathrm{wm} \mathrm{m}^{-2}$ on 17 September compared to $0.6 \mathrm{~g} \mathrm{wm} \mathrm{m}^{-2}$ on 23 July, I. Jäger, pers. comm.) and daphnid abundance was still low $\left(0.6 \mathrm{~g} \mathrm{wm} \mathrm{m}^{-2}\right.$; S. Steiner, pers. comm.). Roach then fed on L. kindtii in the pelagic zone. In the littoral zone, macrophytes were mainly eaten during the summer. The food demand of fish is then increased due to higher water temperatures, and macrophyte biomass is highest. Overall absolute daily rations of an age 3 year roach individual were highest during the summer. This might have been a combined effect of increased water temperature (Jobling, 1994) and increased 
proportions of low digestible prey items. Absolute daily rations of single food items over the season, however, were rather dependent on absolute and relative availability.

For estimating food item specific daily rations by roach, the observed diel habitat and diel shifts constituted an experimental challenge. Bioenergetics modelling has become a widely used tool for estimating fish daily rations. The sensitivity of the model output to changes in physiological parameters has gained much attention (Bartell et al., 1986; Beauchamp et al., 1989; Horpilla \& Peltonen, 1997). Bias can also result, when differences in food composition between day and night samples are not taken into account (Horppila, 1999). This is especially relevant for omnivorous fishes, like roach (Winfield \& Nelson, 1991), which are able to shift between food items of considerably different energy content or digestibility (Beauchamp et al., 1989; Horppila, 1999). Beside differences in percentage diet composition, variances in the feeding intensity over $24 \mathrm{~h}$ are decisive for the proportions of different food items in a fish's absolute daily ration. This is especially relevant for food items that are eaten only for a restricted time period during $24 \mathrm{~h}$.

To quantitatively account for the diel diet shifts of roach in Lake Grosser Vätersee and to estimate daily rations separately for different food categories, a combination of bioenergetics modelling and the evacuation rate method of Elliott \& Persson (1978) was used. Diet proportions that integrated diel variations in diet composition and feeding intensity were obtained for selected dates from the evacuation rate method. Based on these diet proportions, bioenergetics modelling was performed (baseline model) to calculate daily rations of the different food items by an age 3 year roach individual throughout the sampling season. The results gained from the two methods of estimating daily ration were therefore not used as independent measures, but the evacuation rate method was rather a tool to obtain diet composition over $24 \mathrm{~h}$. This is an involved procedure. Severe under- or overestimation of daily rations of daphnids by an age 3 year roach individual resulted, however, when only the daytime or the night-time diet composition was used as a model input. Using the mean of daytime and night-time diet compositions, the calculated daily rations were closer to, but nevertheless still higher than those derived from the baseline model, as the length of the night-time feeding period was not taken into account. Using diet proportions integrated over $24 \mathrm{~h}$ as a model input (baseline model), is therefore the more precise way of dealing with diel shifts in diet composition and feeding intensity by fishes in bioenergetics modelling. Since this is time consuming, the approach to derive diet proportion from repeated qualitative sampling in the course of a day suggested by Horppila (1999) might be a reasonable compromise between sampling effort and model performance, especialy if feeding intensity varies only moderately over the day. Altogether, bioenergetics modelling is more appropriate for monitoring consumption over an extended time period, as it is less subject to the environment conditions at the specific sampling dates than the evacuation rate methods.

The evacuatio rate of age 3 year roach was higher during the daytime, as plant material and detritus were also eaten, compared to the night, when animal diet prevailed (Persson, 1982). Two slightly different methods had to be applied for the day and the night-time evacuation experiments. Serial slaughter experiments 
as used during the day, tend to underestimate evacuation rate, due to handling stress (Ney, 1990). Even if this effect had been at all relevant in this study, the effect of plant material and detritus diet on the excavation rate was still more pronounced. A problem associated with the night-time approach, calculating the evacuation rate from the decrease in intestine fullness, is the presumption that feeding ceases after the onset of darkness (Ney, 1990). This would lead to an underestimation of the evacuation rate and finally of the daily ration. All three $24 \mathrm{~h}$ fisheries in Lake Grosser were conducted at new moon, and no recently ingested food was found in the intestines at night.

The consideration of daytime differences in fish distribution and diet is essential for the assessment of their predation on different prey items. Combining direct with bioenergetics estimates of daily rations allowed diet shifts throughout $24 \mathrm{~h}$ periods to be quantitatively accounted for, and constraints inherent to each of the two approaches for estimating fish daily rations overcome.

We would like to thank C. Helms, U. Baade, M. Mokros, J. Baer and S. Ohmann for their invaluable assistance in field and laboratory work, and two anonymous referees for precious comments on an earlier version of the manuscript. This study was supported by the Deutsche Forschungsgemeinschaft (DFG, Ec 146/2-1+2).

\section{References}

Bartell, S. M., Breck, J. E., Gardner, R. H. \& Brenkert, A. L. (1986). Individual parameter perturbation and error analysis of fish bioenergetics models. Canadian Journal of Fisheries and Aquatic Sciences 43, 160-168.

Beauchamp, D. A., Stewart, D. J. \& Thomas, G. L. (1989). Corroboration of a bioenergetics model for sockeye salmon. Transactions of the American Fisheries Society 118, 597-607.

Bohl, E. (1980). Diel pattern of pelagic distribution and feeding in planktivorous fish. Oecologia 44, 368-375.

Boisclair, D. \& Leggett, W. C. (1988). An in situ experimental evaluation of the Elliott and Persson and the Eggers models for estimating fish daily ration. Canadian Journal of Fisheries and Aquatic Sciences 45, 138-145.

Cummins, K. W. \& Wuycheck, J. C. (1971). Caloric equivalents for investigation in ecological energetics. Mitteilungen der Internationalen Vereinigung für theoretische und angewandte Limnologie 18, 1-158.

Eggers, D. M. (1977). Factors in interpreting data obtained by diel sampling of fish stomachs. Journal of the Fisheries Research Board of Canada 34, 290-294.

Elliott, J. M. \& Persson, L. (1978). The estimation of daily rates of food consumption for fish. Journal of Animal Ecology 47, 977-991.

Gauthier, S. \& Boisclair, D. (1997). The energetic implications of diel onshore-offshore migration by dace (Phoxinus eos $*$ P. neogaeus) in a small oligotrophic lake. Canadian Journal of Fisheries and Aquatic Sciences 54, 1996-2006.

Gayanilo, F. C., Sparre, J. P. \& Pauly, D. (1996). FISAT user's guide. FAO Computerized Information Series/Fisheries $\mathbf{8}$.

Gliwicz, Z. M. \& Jachner, A. (1992). Diel migrtaions of juvenile fish: a ghost of predation past or present? Archiv für Hydrobiologie 124, 385-410.

Gliwicz, Z. M. \& Pijanowska, J. (1989). The role of predation in zooplankton succession. In Plankton Ecology (Sommer, U., ed.), pp. 253-296. New York: Springer.

Haertel, S. S. (2001). Quantification of fish predation on zooplankton in a small mesotrophic lake (Lake Grosser Vätersee). PhD thesis, University of Konstanz. 
Hall, D. J., Werner, E. E., Gilliam, J. F., Mittelbach, G. G., Howard, D., Doner, C. G., Dickerman, J. A. \& Stewart, A. J. (1979). Diel foraging behaviour and prey selection in the golden shiner (Notemigonus chrysoleucas). Journal of the Fisheries Research Board of Canada 36, 1029-1039.

Hanson, P. C., Johnson, T. B., Schindler, D. E. \& Kitchell, J. F. (1997). Fish Bioenergetics 3.0. Madison: University of Madison Sea Grant Institute.

Hasselblad, V. (1966). Estimation of parameters for a mixture of normal distributions. Technometrics 8, 431-446.

Heroux, D. \& Magnan, P. (1996). In situ determination of food daily ration in fish: review and field evaluation. Environmental Biology of Fishes 46, 61-74.

Hewett, S. W. \& Johnson, B. L. (1992). Fish bioenergetics model 2-An upgrade of a generalized bioenergetics model of fish growth for microcomputers. Madison: University of Wisconsin Sea Grant Technical Report WIS-SG-92-250.

Hölker, F. (2000). Bioenergetik dominanter Fischarten (Abramis brama (Linnaeus, 1758) and Rutilus rutilus (Linnaeus, 1758)) in einem eutrophen See Scheswig-HolsteinsÖkophysiologie und Individuen-basierte Modellierung. EcoSys (Suppl.) 32, $1-117$.

Hölker, F. \& Temming, A. (1996). Gastric evacuation in ruffe (Gymnocephalus cernuus (L.)) and the estimation of food consumption from stomach content data of two $24 \mathrm{~h}$ fisheries in the Elbe Estuary. Archive of Fishery and Marine Research 44, 47-67.

Hölker, F., Haertel, S., Steiner, S. \& Mehner, T. (in press). Effects of piscivore-mediated habitat use on growth, diet and zooplankton consumption of roach-An individual-based approach. Freshwater Biology.

Horppila, J. (1999). Diel changes in diet composition of an omnivorous cyprinid - a possible source of error in estimating food consumption. Hydrobiologia 400, 33-39.

Horppila, J. \& Peltonen, H. (1997). A bioenergetics approach on food consumption of roach (Rutilus rutilus (L.)) in a eutrophic lake. Archiv für Hydrobiologie 139, 207-222.

Jobling, M. (1994). Fish Bioenergetics. London: Chapman \& Hall.

Kasprzak, P., Gervais, F., Adrian, R., Weiler, W., Radke, R., Jäger, I., Riest, S., Siedel, U., Schneider, B., Böhme, M., Eckmann, R. \& Walz, N. (2000). Trophic characterization, pelagic food web structure and comparison of two mesotrophic lakes in Brandenburg (Germany). Internationale Revue der gesamten Hydrobiologie 85, 167-189.

Kitchell, J. F., Stewart, D. J. \& Weiniger, D. (1977). Applications of a bioenergetics model to yellow perch (Perca flavescens) and walleye (Stizostedion vitreum vitreum). Journal of the Fisheries Research Board of Canada 34, 1922-1935.

Naud, M. \& Magnan, P. (1988). Diel onshore-offshire migrations in northern redbelly dace, Phoxinus eos (Cope), in relation to prey distribution in a small oligotrophic lake. Canadian Journal of Zoology 66, 1249-1253.

Ney, J. J. (1990). Trophic economics in fisheries: Assessment of demand-supply relationships between predators and prey. Reviews in Aquatic Science 2, 55-81.

Northcote, T. G. (1988). Fish in the structure and function of freshwater ecosystems: a "top-down" view. Canadian Journal of Fisheries and Aquatic Sciences 45, 361-369.

Persson, L. (1982). Rate of food evacuation in roach (Rutilus rutilus) in relation to temperature, and the application of evacuation rate estimates for studies on the rate of food consumption. Freshwater Biology 12, 203-210.

Persson, L. (1983). Food consumption and the significance of detritus and algae to intraspecific competition in roach Rutilus rutilus in a shallow eutrophic lake. OIKOS 41, 118-125.

Persson, L. (1987). Effects of habitat and season on competitive interactions between roach (Rutilus rutilus) and perch (Perca fluviatilis). Oecologia 73, 170-177.

Radke, R. (1998). Strukturbildende Prozesse in Fischartengemeinschaften mesotropher Seen des nordostdeutschen Tieflandes. PhD thesis, University of Konstanz. 
Rice, J. A. \& Cochran, P. A. (1984). Independent evaluation of a bioenergetics model for largemouth bass. Ecology 65, 732-739.

Winfield, I. J. \& Nelson, J. S. (1991). Cyprinid Fishes (Systematics, Biology and Exploitation). London: Chapman \& Hall.

Wurtsbaugh, W. \& Li, H. (1985). Diel migrations of a zooplanktivorous fish (Menidia beryllina) in relation to the distribution of its prey in a large eutrophic lake. Limnology and Oceanography 30, 565-576. 